\title{
83 book reviews
}

\section{Sex in development: science, sexuality and morality in global perspective}

Vincanne Adams and Stacy Leigh Pigg (editors); Duke University Press, Durham, 2005, ISBN 0-8223-3491-7 £15.95 (Pbk) 360p; ISBN 0-8223-3479-8 $£ 64.00$ (Hbk) $360 \mathrm{p}$

In Sex in Development: Science, Sexuality and Morality in Global Perspective, Vincanne Adams and Stacy Leigh Pigg bring together a series of rich and detailed ethnographic studies carried out by anthropologists over the past 10 years in Asia, Africa and Europe. These studies examine how reproductive and sexual health programmes attempt to put into practice a global agenda reflecting the international standards and technologies of medical science. The book aims to demonstrate how modern sexual knowledge and health programmes claim to be value free by 'objectifying' sex and sexuality in universal biological terms, but that they are in practice based on implicit moral assumptions, codes and objectives that combine to attempt to create a universal 'normal' sexuality. The authors also examine the implications of these programmes for diverse local sexual practices, meanings and moralities. The locations represented in the book are subject to a range of international visions of sexuality that circulate in and through political, economic, religious and cultural agendas in the family, community and modernizing postcolonial and postsocialist nations.

The ethnographic studies are organized into three main sections. The first is concerned with examining how existing reproductive identities and gender norms, inherently tied to sexual practices, interact with scientific efforts to create a self-conscious, autonomous subject who identifies his or her subjectivity through a medicalized sexuality considered separate from other domains of social life. Michele Rivkin-Fish examines Russian doctors' resistance to American pharmaceutical representatives' attempts to teach them a 'value-free' way to offer contraceptives to female patients. In Greece, Heather Paxson highlights the moral conflicts women experience as the result of family planning programmes, and in Uganda, Shanti Parikh analyses how recent youth sex education initiatives have resulted in alienating adult relatives, leaving young people to explore sexual risks and pleasures in experimental and sometimes detrimental ways.

The second section is concerned with how ideas about what constitutes 'normal' sex are introduced, and how these normativities depend on health workers identifying local practices as 'backward' and deviant. In Tibet, 
Vincanne Adams studies the tension between Buddhist ideas of fertility and the population control programmes of the Chinese government. In Papua, Leslie Butt examines how Javanese state health workers render deviant the ways in which Dani women challenge existing regimes of power and assert control of their sexuality and choice of partner. Heather Dell's research focuses on the changing sexual practices and moralities expected of Indian prostitutes and middle class wives by men who are influenced by the influx of Western porn and mainstream videos.

The third section focuses on HIV/AIDS prevention initiatives that promote sexual liberalism, and the fallacies of the moral 'high ground' they claim. Vinh-Kim Nguyen's study in the Ivory Coast explores how poverty and local constructions of masculinity influence men's sexual practices, identity construction and responses to the messages of safe sex and sexual openness as strategies for empowerment. In the final study, Lawrence Cohen examines the role and impact of attempts by HIV/AIDS programmes in India to identify different local, male homosexual identity groups and how Indian men's identification with these groups, such as the kothi, connects them to wider political interests and conflicts, such as Muslim-Hindu identity politics.

Overall, this collection makes an important contribution to fledgling debates on sexuality and development in a global context. While sex and sexuality have been an increasingly important element of population and health development programmes, publications dedicated to detailed analyses of these experiences have been scarce. As the editors note, the main contributions to date have emerged from feminist theoretical and ethnographic research, historically focusing on exploring the cultural diversity and meanings of sexuality, gender, reproduction and kinship in different countries and ethnic groups. More recently, this research has moved beyond the study of heterosexuality to explore male same-sex sexualities, connecting with the fields of sexuality studies, queer theory and HIV/AIDS. In this volume, by introducing us to the role and effects of specific scientific health and population discourse, and by making the link with morality, the authors help to expose the values implicit in modern health discourse on sexuality that so often remain unrecognized and unquestioned.

Most notably, while the different contexts each tell a different story, a common feature of all is that development and modernization inherently depend upon and construct the norm of the heterosexual, monogamous, nuclear family that controls its reproduction and takes responsibility for the reduction of health risks. The studies also reveal the greater importance given to the morality and control of female sexuality and reproduction, and the unpredictable, diverse and often contradictory results of the global health agenda in different locations. They confirm that it is only in the field of HIV/AIDS that same-sex sexuality is now recognized as a legitimate topic for research and health initiatives, although only to date in relation to men, and by self-identified gay, male academic 
scholars and non-governmental programmes seeking alternatives to mainstream international and state-sponsored projects.

It is important to note that there is no attempt by the authors to close this book with recommendations for future research, policy-making or practice. This is a major challenge left open for those working in the field of health development, from local health educators to international agencies and health ministries, all under pressure to develop successful reproductive and sexual health models. The volume also leaves unexamined a range of experiences and contexts that have yet to be documented and analysed at an academic level. Experiences in Latin America, for example, include feminist and LGBT (lesbian, gay, bisexual and transgender) academic and activist research, advocacy and community-based initiatives in the field of sexual rights and citizenship. Moreover, to date there are very few studies of women's same-sex sexual histories, practices and identities, or of how women who do not conform to the heterosexual norm are affected by and respond to health and other development programmes. While we wait for more ethnographic research to emerge, it would be helpful for studies of this nature to at least address this issue at a theoretical level, with references to publications available to date (see, e.g., Rosenbloom, 1996; Thadani, 1996; Jolly, 2000; Hawley, 2001; Lind and Share, 2003; Robertson, 2005). In this way researchers could challenge current assumptions that only male same-sex sexual practices, subjectivities and experiences of discrimination exist and merit attention outside modern industrialized nations, especially among low-income sectors of the population that are the priority of international development research, policy and practice.

\section{references}

\section{Carolyn H. Williams}

Hawley, J.C. (2001) editor, Postcolonial Queer: Theoretical Intersections, New York: State University of New York Press.

Jolly, S. (2000) 'Queering development: exploring the links between same-sex sexualities, gender and development' Gender and Development Vol. 8, No. 1.

Lind, A. and Share, J. (2003) 'Queering development: institutionalized heterosexuality in development theory, practice and politics in Latin America', in Bhavnani, K.-K., Foran, J. and Kurian, P.A., editors. Feminist Futures: Re-imagining Women, Culture and Development, London: Zed Books.

Rosenbloom, R. (1996) editor, Unspoken Rules: Sexual Orientation and Women's Human Rights, London: Cassell.

Robertson, J. (2005) editor, Same Sex Cultures and Sexualities: An Anthropological Reader, Oxford: Blackwell Publishing.

Thadani, G. (1996) Sakhiyani: Lesbian Desire in Ancient and Modern India, London and New York: Cassell.

doi: $10.1057 /$ palgrave.fr. 9400288 